OPEN ACCESS

Edited by:

Farid Rahimi,

Australian National University, Australia

Reviewed by:

Oana Sandulescu,

Carol Davila University of Medicine and Pharmacy, Romania

Muhammad Imran Khan,

The University of Haripur, Pakistan

*Correspondence: Jie Wu

zjwujie@zju.edu.cn

Jingjing Ren

3204092@zju.edu.cn

Specialty section

This article was submitted to Infectious Diseases - Surveillance,

Prevention and Treatment,

a section of the journal

Frontiers in Medicine

Received: 13 September 2021 Accepted: 01 November 2021

Published: 13 December 2021

Citation:

Zheng $Y$, Ying $M$, Zhou Y, Lin Y, Ren J and Wu J (2021) Global Burden and Changing Trend of Hepatitis $C$ Virus

Infection in HIV-Positive and

HIV-Negative MSM: A Systematic

Review and Meta-Analysis.

Front. Med. 8:774793.

doi: 10.3389/fmed.2021.774793

\section{Global Burden and Changing Trend of Hepatitis C Virus Infection in HIV-Positive and HIV-Negative MSM: A Systematic Review and Meta-Analysis}

\author{
Yang Zheng ${ }^{1,2}$, Meike Ying ${ }^{2}$, Yuqing Zhou ${ }^{1,3}$, Yushi Lin ${ }^{1}$, Jingjing Ren ${ }^{2 *}$ and Jie Wu ${ }^{1 *}$ \\ ${ }^{1}$ State Key Laboratory for Diagnosis and Treatment of Infectious Diseases, National Clinical Research Center for Infectious \\ Diseases, Collaborative Innovation Center for Diagnosis and Treatment of Infectious Diseases, The First Affiliated Hospital, \\ School of Medicine, Zhejiang University, Hangzhou, China, ${ }^{2}$ Department of General Practice, The First Affiliated Hospital, \\ School of Medicine, Zhejiang University, Hangzhou, China, ${ }^{3}$ Department of Respiratory Medicine, Sir Run Run Shaw \\ Hospital, School of Medicine, Zhejiang University, Hangzhou, China
}

Background: The disease burden of hepatitis C virus (HCV) infection in HIV-positive and HIV-negative men who have sex with men (MSM) is changing. We aim to provide an updated comprehensive estimate of HCV prevalence and incidence among the HIV-positive and HIV-negative MSM population at the country, regional, and global levels and their changing trends over time.

Methods: PubMed, Embase, PsycINFO, CINAHL, and conference databases were searched and eligible records on the prevalence and incidence of HCV antibodies were selected and pooled via a random-effects model. Meta-regression was performed to demonstrate the association between the pooled rates and study year.

Results: A total of 230 articles reporting 245 records from 51 countries with 445,883 participants and 704,249 follow-up person-years were included. The pooled prevalence of HCV in MSM was 5.9\% (95\% Cl: 5.1-6.8), with substantial differences between countries and regions. Low- and lower-middle-income countries (12.3 and 7.0\%) manifested a larger disease burden than high- and upper-middle-income countries (5.8 and 3.8\%). HCV prevalence in HIV-positive MSM was substantially higher than in HIV-negative MSM (8.1 vs. 2.8\%, $p<0.001)$. The pooled incidence of HCV was 8.6 (95\% Cl: $7.2-10.0)$ per 1,000 person-years, with an increasing trend over time, according to meta-regression $(p<0.05)$.

Conclusion: Global HCV prevalence in MSM varies by region and HIV status. Behavior counseling and regular HCV monitoring are needed in HIV-positive subgroups and high-risk regions. Given the upward trend of HCV incidence and sexual risk behaviors, there is also a continued need to reinforce risk-reduction intervention.

Systematic Review Registration: PROSPERO, identifier CRD42020211028; https:// www.crd.york.ac.uk/prospero/.

Keywords: hepatitis C virus (HCV), human immunodeficiency virus (HIV), men who have sex with men (MSM), prevalence, incidence, changing trend 


\section{INTRODUCTION}

Hepatitis C virus (HCV) infection is a global public health threat. It was estimated that there were 71 million persons living with chronic HCV infection worldwide and 1.75 million new HCV infections in 2015 (1). Acute HCV infection persists for $\sim 6$ months and $55-85 \%$ of patients with acute hepatitis $\mathrm{C}$ transition to chronic hepatitis $\mathrm{C}$, which may cause a series of end-stage liver diseases, such as chronic liver disease, cirrhosis, and hepatocellular carcinoma, in $\sim 20-30$ years in some patients (2). Unsafe healthcare practices (including unprotected exposure to blood or blood products) in the past and injection drug use nowadays account for most HCV infections (3).

In men who have sex with men (MSM), an excess risk of sexual HCV transmission has commonly been reported, especially for those who are concurrently infected with HIV. For instance, since the year 2000, several studies have reported an expanding epidemic of sexually transmitted acute HCV infection in HIV-positive MSM in North America, Europe, Australia, and Asia $(4,5)$. Several factors may facilitate sexual transmission of HCV in HIV-positive MSM. HCV viral loads are higher in semen in the presence of HIV and a sufficient quantity of HCV is exposed to the rectum in HIV-infected men, which may increase the infectivity of HCV carriers (6). In addition, behavioral factors such as increased high-risk sexual behavior and decreased precautionary measures are also believed to increase the HCV infection risk for HIV-positive $\operatorname{MSM}(7)$.

Despite a high HCV burden in HIV-positive MSM, HCV prevalence and incidence among HIV-negative MSM have been low and stable in previous studies, which is explained by the sexual behavior, sexual network different from those of HIVpositive MSM and other routes apart from sexual contact (8). Nevertheless, the most updated data revealed a high incidence of HCV in HIV-negative MSM (9). In addition, the identification of sexual network overlap among HIV-positive and HIV-negative MSM that placed HIV-negative MSM at high risk for HCV infection, as suggested that HIV-negative MSM is infected with HCV strains already circulating among HIVpositive MSM (10).

Considering the high HCV incidence and sexual network alternation in the recent years among the MSM population, the overall global HCV burden is expected to substantially change. However, there were few studies reported the updated comprehensive quantitative review of the global HCV burden in the MSM population. A recent meta-analysis focused on the HCV in both the HIV-positive and HIV-negative MSM population between 2000 and 2019, yet it only revealed the prevalence and incidence without further demonstration of their changing trends (11). Therefore, we conducted this updated systematic review and meta-analysis to provide a comprehensive estimate of HCV prevalence and incidence among the HIVpositive and HIV-negative MSM population at the country, regional, and global levels and their changing trends between 1990 and 2021.

\section{METHODS}

\section{Literature Search and Study Inclusion}

This systematic review and meta-analysis were conducted adhering to the Preferred Reporting Items for Systematic Reviews and Meta-Analyses (PRISMA) 2009 guidelines (12). We prospectively submitted the systematic review protocol for registration on the PROSPERO (CRD42020211028). We comprehensively searched the traditional databases of PubMed, Embase, PsycINFO, and CINAHL using a combination of medical subject headings and free text including terms related to HCV, MSM, and prevalence. We also searched HIV/AIDS and hepatology-related conference databases (e.g., International AIDS Society Conference, Conference on Retroviruses and Opportunistic Infections, American Association for the Study of Liver Diseases, European Association for the Study of the Liver) (Supplementary Appendix 1). All the related published papers from January 1, 1990 to July 31, 2021 were identified and subsequently stored using EndNote X9.

Sources were eligible for inclusion; if the study population was exclusively MSM or if MSM could be separated from other population; if the researchers conducted serological testing for anti-HCV and/or HCV RNA; and if the study presented an estimate of anti-HCV prevalence or HCV incidence (defined as antibody seroconversion or positive RNA). Incidence sources were restricted to those in which seroconversion was known to have occurred. Sources were excluded; if the study population was a transgender population; if HCV infection status was selfreported or no information with respect to HCV status was determined; if sources had a sample size of less than 30 or had no information with respect to sample size; if it was HCV reinfection; and if the study was a case report, case series, or review. There were no restrictions on language of publication or the age of the sampled population. Multiple publications with the same data source were excluded with detained the most recent publication.

\section{Data Extraction}

Two authors (Zheng $\mathrm{Y}$ and Ying $\mathrm{M}$ ) screened all the sources for inclusion, with a third senior reviewer $(\mathrm{Wu} \mathrm{J})$ consulted when disagreement occurred. A review of potentially eligible reports was a multistage process, as depicted in the PRISMA flow diagram. We extracted the following information for all the eligible studies: the first author; publication year; country and city of the study; years of study start and end; study design; sample size or follow-up person year (FUPY) of HCV; number of HCVpositive and HCV-negative people; HCV testing methods; and number of concurrent HIV-positive and HIV-negative people.

\section{Outcomes}

To calculate the prevalence of HCV in MSM, we extracted the number of HCV positive and total number of HCV tested. Based on the available literature, we also performed a subgroup analysis to estimate the prevalence of HCV in HIV-positive and HIVnegative MSM. HCV incidence was calculated from subgroups of studies that followed MSM without HCV at baseline for the 
development of $\mathrm{HCV}$, in which the number of $\mathrm{HCV}$ positive and total FUPY were extracted. Country-level pooled rates were further aggregated into the region-level and subregion-level rates of prevalence and incidence according to the United Nations Department of Economic and Social Affairs classification. We also examined the region-level rates of prevalence and incidence when countries were grouped by their income according to the World Bank classification (13).

\section{Quality Assessment}

Included studies were assigned quality scores using the Newcastle-Ottawa Scale (NOS) for cohorts and case-control studies and a modified NOS for cross-sectional studies (14, 15). The NOS assesses three domains of methodology of study including study participant selection (0-4 points), confounder adjustment ( $0-2$ points), and outcome indicator determination (0-3 points). Studies with the NOS score of 7-9 points were defined as high quality, while those with less than 7 points were deemed of low or medium quality (15).

\section{Statistical Analysis}

We conducted a meta-analysis to calculate the pooled prevalence and incidence of HCV infection in MSM and their 95\% CI using a random-effects model given the high heterogeneity expected. The Freeman-Tukey double arcsine transformation of the original positive rate was conducted to stabilize the variance to reduce the effect of extreme values on the pooled positive rate estimate (16). The results were presented as "percent" in the prevalence study and "per 1,000 person-years" in the incidence study with $95 \%$ $\mathrm{CI}$ and heterogeneity was assessed using $I^{2}$. A subgroup analysis was performed to estimate the prevalence of HCV in subgroups by HIV status (positive or negative). We used meta-regression to investigate the changing trend of prevalence and incidence over time. The results were presented with bubble plots with a regression equation. Publication bias was assessed by Egger's test and funnel plot. Sensitivity analyses were conducted to assess the influence of each individual study on the final pooled estimates. Data were analyzed using the $\mathrm{R}$ software (version 4.0.0). $p<0.05$ was deemed as statistically significant.

\section{RESULTS}

\section{Selection, Description, and Quality of Included Studies}

A total of 3,711 articles were screened from the database, of which 820 duplicates were removed and 2,891 unique articles were remained. We excluded 2,457 articles that clearly did not meet the selection criteria by title or abstract screening. A total of 434 articles were assessed for full text. Among them, 204 articles were further excluded because MSM population information could not be extracted $(n=136)$, duplicated data $(n=32)$, HCV testing method not mentioned $(n=27)$, and HCV incidence not provided $(n=9)$. Finally, a total of 230 articles reporting 245 records from 51 countries with 445,883 participants and 704,249 FUPY were included after full-text review (Figure 1). Published year ranges from 1990 to 2021. Sample size ranged from 26 to 129,136 in prevalence studies and 282 to 315,392 FUPY in incidence studies. All the articles used HCV antibody test. Crosssectional $(n=155)$ and cohort $(n=47)$ studies were the major study designs. A total of 94 records reported HCV infection in 54,530 HIV-positive MSM, while 49 records reported HCV infection in 45,937 HIV-negative MSM. Other characteristics of the included studies are shown in Supplementary Appendix 2.

\section{Hepatitis C Virus Prevalence and Changing Trend Over Time}

Across 196 records screening for HCV infection (anti-HCV positive) in 445,883 participants, the pooled prevalence of $\mathrm{HCV}$ in MSM was 5.9\% (95\% CI: 5.1-6.8) globally, with estimates ranging from 0.6 to $63.5 \%\left(I^{2}=99 \%\right.$, Egger's test for bias, $p<0.05)$. The results of the publication bias and influential analysis are shown in Supplementary Appendices 3, 4. The omission of an individual study resulted in pooled estimates ranging from 5.7 to $6.0 \%$. Table $\mathbf{1}$ and Figure $2 \mathrm{~A}$ present the prevalence and number of reported participants by country. The countries with the highest HCV burden were Mexico (63.5\%, 95\% CI: 0.0-100.0), Malaysia (59.2\%, 95\% CI: 51.9-66.3), Thailand (41.4\%, 95\% CI: 4.6-85.3), Mongolia (36.0\%, 95\% CI: $23.2-$ 49.9), and Indonesia (32.5\%, 95\% CI: 22.4-43.4). Countries with the lowest HCV prevalence were Togo (0.6\%, 95\% CI: 0.0-2.5), Mali (0.6\%, 95\% CI: 0.0-1.9), Lebanon (0.7\%, 95\% CI: $0.3-$ $1.3)$, Brazil (0.8\%, 95\% CI: $0.3-1.5)$, and China (1.2\%, 95\% CI: 1.0-1.5). Regions with the highest reported HCV burden were Central America (63.5\%, 95\% CI: 0.0-100.0), Southeast Asia (29.0\%, 95\% CI: 14.4-46.1), and Southern Asia (15.1\%, 95\% CI: 0.3-44.5). Regions with the lowest reported HCV burden were Western Asia (1.3\%, 95\% CI: 0.0-4.6), Eastern Asia (1.9\%, 95\% CI: 1.6-2.3), and Western Africa (2.2\%, 95\% CI: 0.5-5.0). We found a substantial difference between high-/upper-middleincome countries (5.8 and 3.8\%) and low-/lower-middle-income countries (12.3 and 7.0\%), as shown in Table 2. Forest plots are given in Supplementary Appendix 5.

To reveal the changing trend of HCV prevalence over time accurately, we also performed a meta-regression to investigate the association between prevalence and the date of study in Figure 3A. No statistically significant association $(p>0.05)$ was demonstrated between the overall HCV prevalence and the year of study end, which indicated that HCV prevalence was relatively stable over 30 years.

\section{Hepatitis C Virus Prevalence in Participants With Different HIV Infection Statuses}

Across 94 records reporting anti-HCV positivity in 54,530 HIV-positive MSM participants, the pooled prevalence of $\mathrm{HCV}$ in HIV-positive MSM was $8.1 \%$ (95\% CI, 6.8-9.4) $\left(I^{2}=97 \%\right)$. As shown in Table 3 and Figure 2B, Indonesia (100.0\%, 95\% CI: 30.3-100.0), Vietnam (84.1\%, 95\% CI: 77.7-89.7), Libya (83.3\%, 95\% CI: 56.1-99.6), Italy (22.6\%, 95\% CI: 9.1-39.6), and Argentina (21.0\%, 95\% CI: 8.4$37.3)$ had a high prevalence exceeding 20\%. Japan $(2.1 \%$, 95\% CI: 1.3-3.0) and Denmark (2.4\%, 95\% CI: 0.0-7.0) had the lowest prevalence. At the regional level, Asia (7.4\%, 95\% CI: 3.8-11.7) and Europe (6.3\%, 95\% CI: 5.1-7.6), 


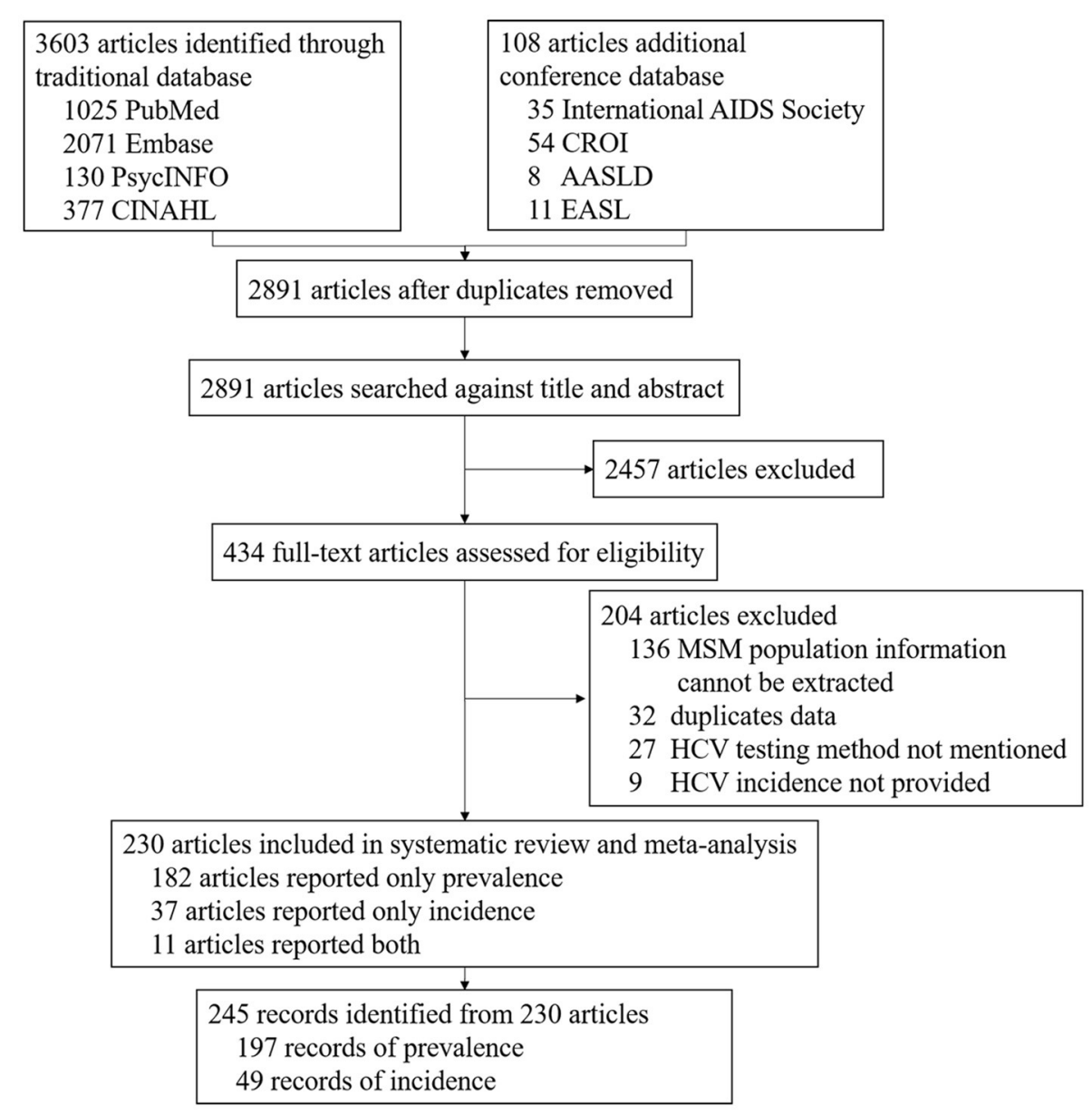

FIGURE 1 | Flowchart of studies selection process.

particularly Eastern Asia and Northern/Western Europe, had lower HCV burdens than Africa (10.6\%, 95\% CI: 2.9-21.5), North America (11.4\%, 95\% CI: 8.9-14.2), Latin America (20.1\%, 95\% CI: 11.8-29.8), and Oceania (11.6\%, 95\% CI: $10.6-$ 12.6). High-income countries tended to have the least burden of $\mathrm{HCV}$, with a pooled prevalence of $7.7 \%$ (95\% CI: $6.5-$ 8.9).

A total of 49 studies reported anti-HCV positivity in 45,937 HIV-negative MSM participants. The estimated pooled prevalence was $2.8 \%$ (95\% CI: $1.9-4.0)\left(I^{2}=96 \%\right)$, which was substantially lower than that of HIV-positive patients $(p<$ 0.001). Table 3 and Figure 2C present a few countries, such as Mongolia (36.0\%, 95\% CI: 23.2-49.9), Indonesia (30.7\%, 95\% CI: 20.7-41.6), and Vietnam (19.9\%, 95\% CI: 17.9-22.1), that were still faced with a high prevalence, while most other countries only had a fairly low prevalence $<3 \%$. Africa $(4.6 \%$, 95\% CI: $1.9-8.4)$ and Asia (5.2\%, 95\% CI: 0.8-12.4) had the highest prevalence, followed by North America (4.4\%, 95\% CI: 2.2-7.2), Latin America (3.2\%, 95\% CI: 1.7-5.1), Oceania (2.2\%, 95\% CI: 0.1-6.5), and Europe (1.3\%, 95\% CI: 0.7-2.1). A significant difference was found between high-/upper-middle income countries (2.0 and 1.1\%) and low-/lower-middle-income countries (19.6 and $11.0 \%)$.

\section{Hepatitis C Virus Incidence and Changing Trend Over Time}

A total of 49 cohort studies reported the new development of HCV infection in 704,249 patients with FUPY. The pooled incidence of $\mathrm{HCV}$ was 8.6 (95\% CI: 7.2-10.0) per 1,000 person-years $\left(I^{2}=96 \%\right.$, Egger's test for bias, $p=$ 0.1002). The results of the influential analysis are shown in Supplementary Appendices 3, 4. The omission of an individual study resulted in pooled estimates ranging from 8.2 to 8.8 per 1,000 person-years. Table $\mathbf{1}$ and Figure 2D present the incidence and FUPY by country. Germany (16.4, 95\% CI: 13.3-19.7), Netherlands (11.5, 95\% CI: 5.1-20.5), and Australia (11.8, 95\% CI: 5.3-21.0) had the highest incidence, while China (2.0, 95\% CI: 0.0-8.5), Hong Kong (2.2, 95\% CI: 1.2-3.6), and South Korea (2.6, 95\% CI: 0.6-5.9) had the lowest incidence. At the regional level, Oceania had the highest incidence, followed by Europe and Northern America, and Asia had the lowest incidence. No 
TABLE 1 | Estimates of anti-HCV prevalence and incidence by geographic region.

\begin{tabular}{|c|c|c|c|c|c|c|}
\hline Geographic region & \multicolumn{3}{|c|}{ Prevalence } & \multicolumn{3}{|c|}{ Incidence } \\
\hline Asia & 46 & 307,980 & $4.6(3.8-5.5)$ & 7 & 34,650 & $6.4(2.0-13.0)$ \\
\hline Eastern Asia & 33 & 298,609 & $1.9(1.6-2.3)$ & 6 & 30,638 & $5.5(1.0-13.3)$ \\
\hline China & 20 & 284,596 & $1.2(1.0-1.5)$ & 1 & 507 & $2.0(0.0-8.5)$ \\
\hline Mongolia & 1 & 50 & $36.0(23.2-49.9)$ & & & \\
\hline South Korea & 1 & 320 & $4.1(2.1-6.5)$ & 1 & 1,550 & $2.6(0.6-5.9)$ \\
\hline Taiwan Province & 10 & 12,575 & $3.2(2.1-4.4)$ & 2 & 20,040 & $9.7(0.5-30.0)$ \\
\hline South-Eastern Asia & 8 & 2,406 & $29.0(14.4-46.1)$ & 1 & 4,012 & $12.5(9.2-16.1)$ \\
\hline Indonesia & 1 & 77 & $32.5(22.4-43.4)$ & & & \\
\hline Thailand & 2 & 108 & $41.4(4.6-85.3)$ & & & \\
\hline Vietnam & 3 & 1,865 & $22.6(4.9-47.8)$ & & & \\
\hline Southern Asia & 3 & 5,514 & $15.1(0.3-44.5)$ & & & \\
\hline Afghanistan & 1 & 124 & $30.6(22.8-39.1)$ & & & \\
\hline India & 1 & 4,994 & $1.3(1.0-1.6)$ & & & \\
\hline Pakistan & 1 & 396 & $23.5(19.4-27.8)$ & & & \\
\hline Western Asia & 2 & 1,451 & $1.3(0.0-4.6)$ & & & \\
\hline Lebanon & 1 & 1,351 & $0.7(0.3-1.3)$ & & & \\
\hline Turkey & 1 & 100 & $3.0(0.4-7.5)$ & & & \\
\hline Europe & 84 & 86,525 & $5.3(3.8-6.9)$ & $26^{*}$ & 269,160 & $8.9(7.0-11.1)$ \\
\hline Eastern Europe & 2 & 441 & $4.5(0.9-10.1)$ & & & \\
\hline United Kingdom & 20 & 24,233 & $5.6(1.6-11.7)$ & 3 & 86,237 & $8.5(7.9-9.1)$ \\
\hline Southern Europe & 21 & 8,934 & $6.4(4.6-8.6)$ & 5 & 14,001 & $7.5(4.0-11.9)$ \\
\hline Croatia & 2 & 565 & $2.6(1.4-4.2)$ & & & \\
\hline Greece & 1 & 124 & $8.1(3.8-13.6)$ & & & \\
\hline Italy & 7 & 1,826 & $8.1(4.8-12.2)$ & 2 & 4,700 & $7.2(0.7-19.5)$ \\
\hline Spain & 11 & 6,419 & $6.3(3.7-9.4)$ & 3 & 9,301 & $8.4(3.2-16.0)$ \\
\hline Western Europe & 35 & 51,151 & $4.7(3.6-5.9)$ & 16 & 146,510 & $10.2(7.1-13.9)$ \\
\hline Austria & 1 & 823 & $3.0(2.0-4.3)$ & 1 & 4,892 & $7.4(5.1-10.0)$ \\
\hline Belgium & 3 & 641 & $3.9(0.9-8.8)$ & 1 & 318 & $28.3(12.5-49.8)$ \\
\hline France & 8 & 15,783 & $4.2(2.1-7.0)$ & 4 & 59,728 & $7.4(4.8-10.5)$ \\
\hline Germany & 5 & 8,731 & $9.7(3.3-19.0)$ & 1 & 6,054 & $16.4(13.3-19.7)$ \\
\hline Netherlands & 9 & 8,311 & $4.9(2.5-8.0)$ & 8 & 51,811 & $11.5(5.1-20.5)$ \\
\hline Switzerland & 9 & 16,862 & $3.2(2.0-4.6)$ & 1 & 23,707 & $4.3(3.5-5.1)$ \\
\hline Africa & 13 & 5,557 & $4.3(2.3-6.9)$ & & & \\
\hline Eastern Africa & 3 & 1,427 & $9.6(3.7-17.8)$ & & & \\
\hline Tanzania & 3 & 1,427 & $9.6(3.7-17.8)$ & & & \\
\hline Northern Africa & 1 & 224 & $8.5(5.2-12.5)$ & & & \\
\hline Libya & 1 & 224 & $8.5(5.2-12.5)$ & & & \\
\hline
\end{tabular}


TABLE 1 | Continued

\begin{tabular}{|c|c|c|c|c|c|c|}
\hline \multirow[t]{2}{*}{ Geographic region } & \multicolumn{3}{|c|}{ Prevalence } & \multicolumn{3}{|c|}{ Incidence } \\
\hline & Record & Participant & $\begin{array}{c}\text { Pooled prevalence } \\
\text { estimates, \% (95\% Cl) }\end{array}$ & Record & $\begin{array}{l}\text { Follow up } \\
\text { person year }\end{array}$ & $\begin{array}{l}\text { Pooled incidence estimates, } \\
\qquad / 1,000 \text { py }(95 \% \mathrm{Cl})\end{array}$ \\
\hline Southern Africa & 3 & 1,572 & $3.4(2.1-5.1)$ & & & \\
\hline South Africa & 3 & 1,572 & $3.4(2.1-5.1)$ & & & \\
\hline Western Africa & 6 & 2,334 & $2.2(0.5-5.0)$ & & & \\
\hline Burkina Faso & 2 & 512 & $5.0(0.0-18.6)$ & & & \\
\hline Cote d'Ivoire & 1 & 206 & $1.0(0.0-2.9)$ & & & \\
\hline Mali & 1 & 320 & $0.6(0.0-1.9)$ & & & \\
\hline Nigeria & 1 & 1,125 & $3.1(2.2-4.2)$ & & & \\
\hline Togo & 1 & 171 & $0.6(0.0-2.5)$ & & & \\
\hline Northern America & 33 & 33,067 & 7.8 (5.9-9.9) & 10 & 371,436 & $7.4(5.3-9.9)$ \\
\hline Canada & 9 & 5,618 & $9.1(4.5-15.0)$ & 3 & 11,269 & $4.5(3.3-5.9)$ \\
\hline United States & 24 & 27,449 & $7.3(5.3-9.7)$ & 7 & 360,167 & $8.3(5.6-11.5)$ \\
\hline \multicolumn{7}{|l|}{ Latin } \\
\hline America/Caribbean & 15 & 6,890 & $8.7(4.1-14.8)$ & & & \\
\hline Caribbean & 2 & 1,429 & $2.7(1.9-3.7)$ & & & \\
\hline Dominican Republic & 1 & 1,388 & $3.2(2.3-4.2)$ & & & \\
\hline Puerto Rico & 1 & 41 & $4.9(0.1-14.1)$ & & & \\
\hline Central America & 2 & 177 & $63.5(0.0-100.0)$ & & & \\
\hline Mexico & 2 & 177 & $63.5(0.0-100.0)$ & & & \\
\hline South America & 11 & 5,284 & $4.1(2.3-6.3)$ & & & \\
\hline Argentina & 6 & 2,668 & $6.5(3.2-10.9)$ & & & \\
\hline Brazil & 3 & 1,117 & $0.8(0.3-1.5)$ & & & \\
\hline Colombia & 1 & 1,100 & $2.1(1.3-3.0)$ & & & \\
\hline Peru & 1 & 399 & $3.8(2.1-5.9)$ & & & \\
\hline Oceania & 5 & 5,864 & $7.6(3.6-12.8)$ & 6 & 29,033 & $11.8(5.3-21.0)$ \\
\hline Australia & 5 & 5,864 & $7.6(3.6-12.8)$ & 6 & 29,033 & 11.8 (5.3-21.0) \\
\hline Global & 196 & 445,883 & $5.9(5.1-6.8)$ & 49 & 704,249 & $8.6(7.2-10.0)$ \\
\hline
\end{tabular}

*There is a multi-center incidence study conduct in the whole Europe.

$\mathrm{HCV}$, hepatitis C virus; $\mathrm{Cl}$, confidence interval.

Bold values represent results at the global or regional level, and non-bold values represent results at national level.

data were identified in Africa and Latin America. Almost all the studies were conducted in high-income countries.

Meta-regression demonstrated an association between $\mathrm{HCV}$ incidence and the year a study ended $(p<0.05)$ in Figure 3B. There was an increasing trend of incidence over time from 0.8/1,000 person-years (95\% CI: $0.1-1.9$ ) in 1989 to $14.1 / 1,000$ person-years (95\% CI: 4.6-28.2) in 2021.

\section{DISCUSSION}

This global large-scale meta-analysis provided a comprehensive overview of the HCV prevalence and incidence in the MSM population and the changing trend over time. We indicated that the anti-HCV prevalence is highest in Central America and Southeast Asia in the MSM population. HIV-positive MSM had a much higher HCV prevalence than HIV-negative MSM. An upward trend of incidence was observed globally, especially in developed countries (US, Europe, and Australia), where sexual risk behaviors in MSM were observed increasing substantially (17).
This study found a substantially high $\mathrm{HCV}$ prevalence of $5.9 \%$ in the MSM population. Compared with the general population, MSM was more prone to conduct high-risk sexual behaviors and had more common $\mathrm{HCV}$ infection. According to the WHO data, the estimated $\mathrm{HCV}$ prevalence in the general population was $1.5-2.3 \%$ in the most affected regions and $0.5-$ $1.0 \%$ in the other regions (18). Another global epidemiological systematic review revealed that the average HCV prevalence in the general population was $1.6 \%(1.3-2.1 \%)$ in 2014 (19). However, compared to other high-risk populations, the $\mathrm{HCV}$ prevalence identified in MSM was substantially lower. For example, as many as 52.3\% (95\% CI: 42.4-62.1) of people who inject drugs (PWID) were found to be anti-HCV positive in a global study (20). Another meta-analysis consisted of mainly American, European, and Iranian participants and found that as many as $20.3 \%$ (95\% CI: $15.5-25.2)$ of homeless people were HCV infected (21). Data from 46 countries from 2005 to 2015 also revealed that $15.1 \%$ of prisoners were anti-HCV positive, with the six WHO regions exceeding 10\% (22). The observation that high HCV prevalence in homeless people and prisoners was 


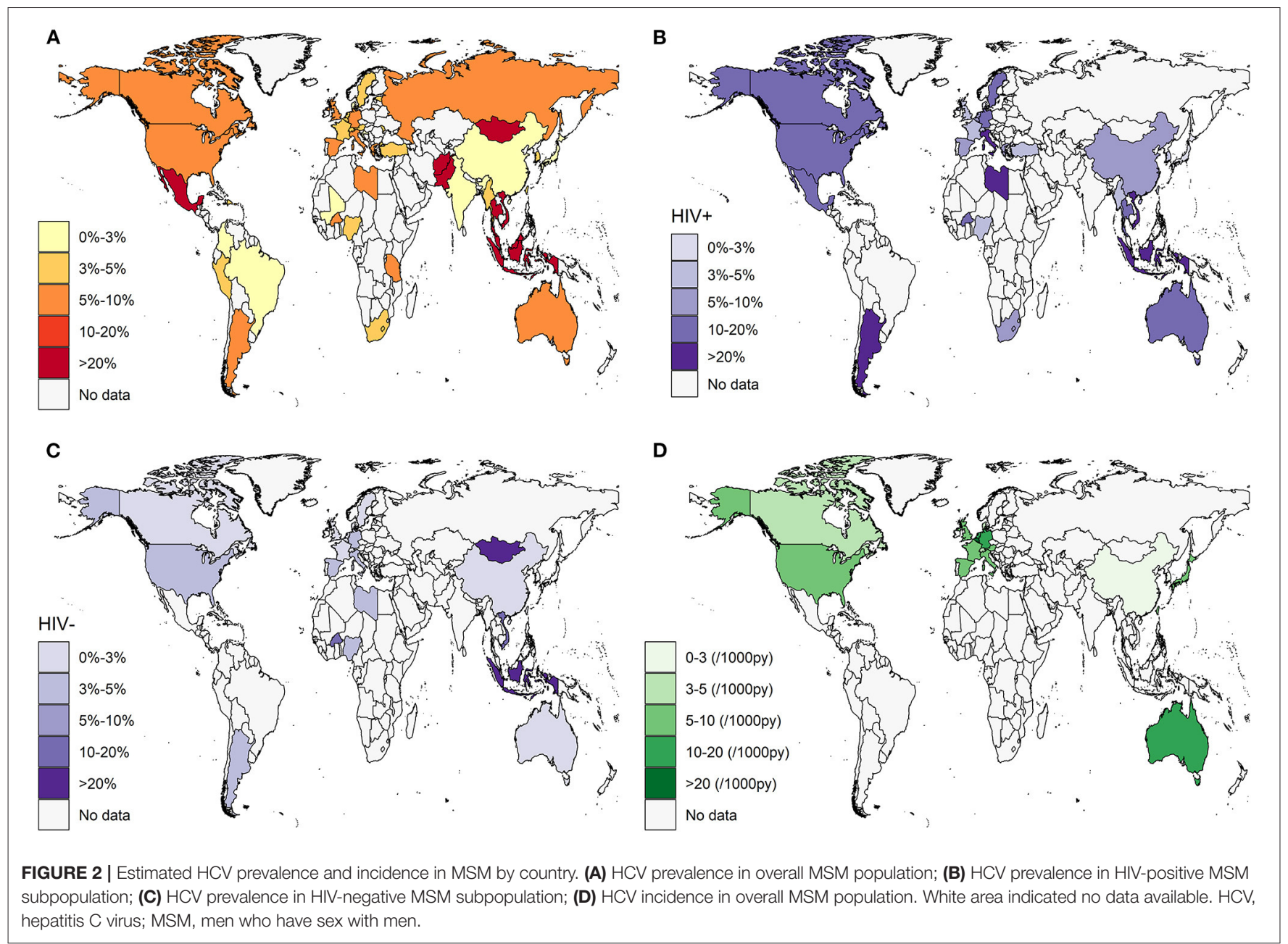

TABLE 2 | Estimated of anti-HCV prevalence and incidence by income level.

\begin{tabular}{|c|c|c|c|c|}
\hline World Bank region & $\begin{array}{c}\text { High } \\
\text { income }\end{array}$ & $\begin{array}{l}\text { Upper-mid } \\
\text { income }\end{array}$ & $\begin{array}{l}\text { Lower-mid } \\
\text { income }\end{array}$ & $\begin{array}{c}\text { Low } \\
\text { income }\end{array}$ \\
\hline \multicolumn{5}{|l|}{ Overall prevalence } \\
\hline Participant & 141,687 & 292,361 & 9,281 & 2,554 \\
\hline Pooled rate, \% (95\% Cl) & $5.8(4.8-6.9)$ & $3.8(3.1-4.6)$ & $12.3(5.1-22.0)$ & $7.0(2.5-13.3)$ \\
\hline Participant & 50,681 & 3,372 & 467 & 10 \\
\hline Pooled rate, \% (95\% Cl) & $7.7(6.5-8.9)$ & $8.2(4.3-13.1)$ & $37.6(0.0-92.5)$ & $10.0(0.0-38.1)$ \\
\hline \multicolumn{5}{|c|}{ Subgroup prevalence in HIV- MSM } \\
\hline Record & 39 & 5 & 4 & 1 \\
\hline Participant & 25,904 & 17,276 & 2,438 & 319 \\
\hline Pooled rate, $/ 1,000$ py $(95 \% \mathrm{Cl})$ & $8.7(7.3-10.2)$ & $2.0(0.0-8.5)$ & I & 1 \\
\hline
\end{tabular}

Country's income level is categorized into high income, upper-middle income, lower-middle income, and low income in accordance with the World Bank classification. $\mathrm{HCV}$, hepatitis C virus; $\mathrm{Cl}$, confidence interval; HIV, human immunodeficiency virus; MSM, men who have sex with men. 


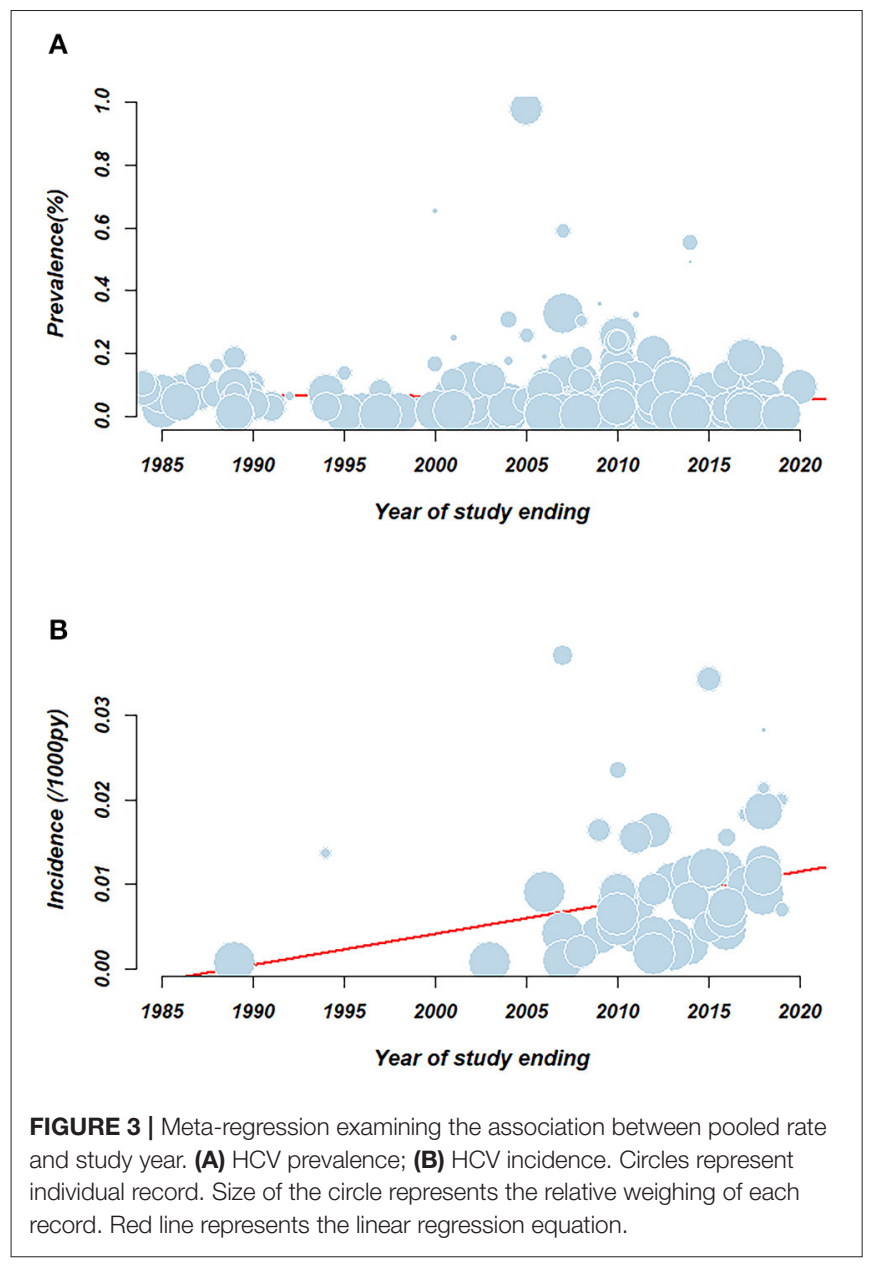

believed to be highly connected with intravenous drug use, which may largely increase blood-borne virus transmission $(21,22)$. Although not as severe as PWID, the MSM population still had a considerably higher HCV disease burden compared with the general population, which was non-negligible.

This study also illustrated a wide variation in the prevalence of HCV in MSM among countries and regions. We found that Southeast and Southern Asia, Central America, the Mediterranean, and Eastern Africa had a high prevalence, which was consistent in geographic pattern with that in the general population $(19,23)$. However, there was still a subtle difference between this study and other studies. In this study, data from the Sub-Saharan population, which was considered a high-prevalence area in general population studies, were not available (24). Notably, Southeast Asia was identified as a high HCV-prevalence area in MSM in this study, but not in the general population (anti-HCV prevalence $1.0 \%$, viremic prevalence $0.7 \%)(19,25)$. The reasons could be multifaceted. First, high rates of drug use that strikingly increased the risk for HCV transmission have been reported among MSM from multiple Southeast Asian countries (26). Second, morbidity of $\mathrm{HCV}$ in the MSM population has received less attention in this region, as the 2017 Thai guideline did not recommend testing MSM for HCV on a regular basis (27). Third, the local social culture of conforming to masculine norms and limited acceptance could also put pressure on the MSM population to engage in a series of high-risk behaviors and limited use of harm-reduction services (28). Thus, in addition to conventional strategies of behavioral counseling and health education, regular HCV testing in MSM is emphasized and more efforts are warranted to eliminate sociocultural biases and discrimination toward MSM in Southeast Asia.

This study revealed a particularly high $\mathrm{HCV}$ prevalence in HIV-positive MSM. The results aligned with a recent global meta-analysis (29). Both the behavioral and biological factors have been proposed to explain the potential susceptibility of HCV transmission in patients with HIV (30). Biologically, HIV-induced immune impairment might compromise the gastrointestinal mucosa barrier and facilitate HCV transmission (31); additionally, impaired T- and natural killer (NK) cells in patients with HIV could lead to lower rates of $\mathrm{HCV}$ seroclearance (32). However, a modeling study indicated that behavioral factors (e.g., sexual behavior risk heterogeneity and HIV preferential mixing) played a pivotal role (30). Multiple studies have shown increased high-risk sexual behavior and decreased precautionary measures among HIV-positive MSM after adopting HIV pre-exposure prophylaxis (PrEP) and a subsequent increase in the incidence of $\mathrm{HCV}$ and other sexually transmitted infections (STIs) $(33,34)$. These findings highlight the urgency of risk-reduction interventions and the importance of routine HCV testing in HIV-positive MSM for all the countries.

A total of 39 studies mainly from Eastern Asia, Europe, North America, and Oceania reported an overall HCV incidence of 8.6/1,000 person-years with an increasing trend over time. Based on this study, developed countries had higher incidences and more significant incidence increases than Asian countries. The findings were consistent with other studies. A European Collaboration reported an increase of $\mathrm{HCV}$ incidence from 5.5-8.1 to 23.4-51.1/1,000 person-years during 1995-2007 in 3,014 MSM (35). Another European study also observed a significantly increasing incidence from 0.7 to $18 / 1,000$ personyears during 1990-2014 in 5,941 MSM (36). Similar trend of HCV incidence was also observed in an American MSM cohort, with the lowest of $4.9 / 1,000$ person-years growing to $30.1 / 1,000$ person-years during 2000-2015 (37). In contrast, there was only 2-fold increase of incidence in Asian cohorts (from 2.28 to 4.94/1,000 person-years during 2006-2013 and from 14.28 to $25.38 / 1,000$ person-years during 2011-2018) (38, 39). In fact, $\mathrm{HCV}$ incidence in MSM was closely connected with sexual risk behaviors; an increase in these behaviors was proposed as an important reason for increasing incidence (37, 39). Sexual risk behaviors among MSM in developed countries have been higher than in Asian countries including sexualized drug use $(40,41)$ and condomless anal sex $(42,43)$. Moreover, sexual risk behaviors of MSM in developed countries are still increasing significantly over time, as seen in the US (44), Denmark (45), UK (46), France (47), and Netherlands (48). The probable causes are condom fatigue, complacency about HIV, availability of other prevention options, optimism about 
TABLE 3 | Estimates of anti-HCV prevalence by HIV status.

\begin{tabular}{|c|c|c|c|c|c|c|}
\hline \multirow[t]{2}{*}{ Geographic region } & \multicolumn{3}{|c|}{ HIV+ MSM } & \multicolumn{3}{|c|}{ HIV- MSM } \\
\hline & Record & Participant & $\begin{array}{c}\text { Pooled prevalence } \\
\text { estimates, \% (95\% Cl) }\end{array}$ & Record & Participant & $\begin{array}{c}\text { Pooled prevalence } \\
\text { estimates, \% ( } 95 \% \mathrm{Cl})\end{array}$ \\
\hline Asia & 21 & 9,412 & $7.4(3.8-11.7)$ & 9 & 19,207 & $5.2(0.8-12.4)$ \\
\hline Eastern Asia & 16 & 8,946 & $4.6(2.9-6.8)$ & 7 & 17,757 & $0.7(0.0-2.1)$ \\
\hline China & 7 & 2,552 & $5.6(1.7-11.3)$ & 3 & 16,635 & $0.6(0.5-0.8)$ \\
\hline Japan & 1 & 1,068 & $2.1(1.3-3.0)$ & & & \\
\hline Mongolia & & & & 1 & 50 & $36.0(23.2-49.9)$ \\
\hline South Korea & 1 & 320 & $4.1(2.1-6.5)$ & & & \\
\hline Taiwan Province & 7 & 5,006 & $4.7(2.4-7.6)$ & 3 & 1,072 & $0.0(0.0-0.0)$ \\
\hline South-Eastern Asia & 4 & 366 & $44.9(0.0-98.8)$ & 2 & 1,450 & $24.0(14.4-35.1)$ \\
\hline Indonesia & 1 & 2 & $100(30.3-100.0)$ & 1 & 75 & 30.7 (20.7-41.6) \\
\hline Myanmar & 1 & 177 & $3.4(1.1-6.7)$ & & & \\
\hline Thailand & 1 & 42 & $19.0(8.4-32.5)$ & & & \\
\hline Vietnam & 1 & 145 & $84.1(77.7-89.7)$ & 1 & 1,375 & $19.9(17.9-22.1)$ \\
\hline Western Asia & 1 & 100 & $3.0(0.4-7.5)$ & & & \\
\hline Turkey & 1 & 100 & $3.0(0.4-7.5)$ & & & \\
\hline Europe & 45 & 26,997 & $6.3(5.1-7.6)$ & 21 & 13,655 & $1.3(0.7-2.1)$ \\
\hline Northern Europe & 9 & 1,935 & $4.5(1.8-8.1)$ & 7 & 2,893 & $0.4(0.2-0.8)$ \\
\hline Denmark & 1 & 84 & $2.4(0.0-7.0)$ & 1 & 63 & $0.0(0.0-0.0)$ \\
\hline Sweden & 1 & 59 & 13.6 (5.8-23.6) & 2 & 1,056 & $0.1(0.0-0.6)$ \\
\hline United Kingdom & 7 & 1,792 & $3.9(1.1-7.9)$ & 4 & 1,774 & $0.7(0.2-1.4)$ \\
\hline Southern Europe & 8 & 1,278 & 12.7 (5.6-21.9) & 3 & 895 & $3.6(1.9-5.6)$ \\
\hline Greece & 1 & 124 & $8.1(3.8-13.6)$ & & & \\
\hline Italy & 3 & 200 & $22.6(9.1-39.6)$ & 1 & 519 & $4.4(2.8-6.4)$ \\
\hline Spain & 4 & 954 & $8.1(3.8-13.6)$ & 2 & 376 & $3.0(0.7-6.6)$ \\
\hline Western Europe & 28 & 23,784 & $5.6(4.4-7.0)$ & 11 & 9,867 & $1.4(0.6-2.5)$ \\
\hline Belgium & 3 & 509 & $5.0(2.4-8.3)$ & 1 & 132 & $0.8(0.0-3.2)$ \\
\hline France & 7 & 3,456 & $4.7(3.4-6.2)$ & 2 & 2,278 & $1.3(0.0-8.7)$ \\
\hline Germany & 4 & 3,084 & $12.4(6.5-19.8)$ & 2 & 3,702 & $4.1(0.0-22.7)$ \\
\hline Netherlands & 7 & 4,936 & $5.8(2.2-10.6)$ & 5 & 2,934 & $1.4(0.4-3.0)$ \\
\hline Switzerland & 7 & 11,799 & $3.8(2.9-4.8)$ & 1 & 821 & $0.4(0.0-0.9)$ \\
\hline Africa & 5 & 770 & $10.6(2.9-21.5)$ & 4 & 1,898 & $4.6(1.9-8.4)$ \\
\hline Northern Africa & 1 & 12 & 83.3 (56.1-99.6) & 1 & 215 & $4.2(1.9-7.3)$ \\
\hline Libya & 1 & 12 & 83.3 (56.1-99.6) & 1 & 215 & $4.2(1.9-7.3)$ \\
\hline Southern Africa & 2 & 605 & $4.3(2.1-7.0)$ & 1 & 426 & $2.3(1.1-4.0)$ \\
\hline South Africa & 2 & 605 & $4.3(2.1-7.0)$ & 1 & 426 & $2.3(1.1-4.0)$ \\
\hline Western Africa & 2 & 153 & $3.6(0.7-7.8)$ & 2 & 1,257 & $6.3(0.8-16.3)$ \\
\hline Burkina Faso & 1 & 10 & $10.0(0.0-38.1)$ & 1 & 319 & $11.0(7.8-14.7)$ \\
\hline Nigeria & 1 & 143 & $4.9(1.9-9.1)$ & 1 & 938 & $3.0(2.0-4.2)$ \\
\hline Northern America & 17 & 13,099 & 11.4 (8.9-14.2) & 12 & 9,411 & $4.4(2.2-7.2)$ \\
\hline Canada & 4 & 1,409 & $11.2(4.7-20.1)$ & 3 & 746 & $2.8(1.6-4.2)$ \\
\hline United States & 13 & 11,690 & $11.5(8.7-14.7)$ & 9 & 8,665 & $4.6(2.0-8.2)$ \\
\hline \multicolumn{7}{|l|}{ Latin } \\
\hline America/Caribbean & 3 & 246 & $20.1(11.8-29.8)$ & 1 & 410 & $3.2(1.7-5.1)$ \\
\hline Central America & 1 & 61 & $18.0(9.3-28.8)$ & & & \\
\hline Mexico & 1 & 61 & 18.0 (9.3-28.8) & & & \\
\hline South America & 2 & 185 & $21.0(8.4-37.3)$ & 1 & 410 & $3.2(1.7-5.1)$ \\
\hline Argentina & 2 & 185 & $21.0(8.4-37.3)$ & 1 & 410 & $3.2(1.7-5.1)$ \\
\hline Oceania & 3 & 4,006 & $11.6(10.6-12.6)$ & 2 & 1,356 & $2.2(0.1-6.5)$ \\
\hline Australia & 3 & 4,006 & $11.6(10.6-12.6)$ & 2 & 1,356 & $2.2(0.1-6.5)$ \\
\hline Global & 94 & 54,530 & $8.1(6.8-9.4)$ & 49 & 45,937 & $2.8(1.9-4.0)$ \\
\hline
\end{tabular}

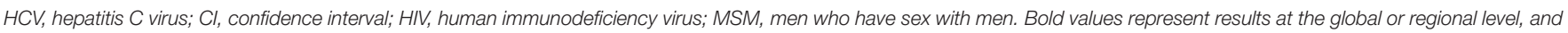
non-bold values represent results at national level. 
HIV treatments, and the adoption of seroadaptive strategies in the above countries (17). Thus, there is a continued need to reinforce risk-reduction intervention for MSM who engage in unprotected sex and to offer regular $\mathrm{HCV}$ monitoring for all the MSM.

Although an increasing $\mathrm{HCV}$ incidence was demonstrated by meta-regression, the HCV prevalence was found stable prevalence over time. It was thought to be associated with improved HCV screening and treatment. Notably, HCV treatment had evolved rapidly over the past decades from pegylated interferon in 2000 to the launch of directacting antiviral (DAA) drug in 2010 (49). Especially after 2015, the expanded availability of DAA opened a new era of "elimination HCV" (50). In addition to advances in treatment, HCV screening recommendation had also updated and expanded (51). Thus, despite an upward trend of incidence, the increase in cure rate may ensure a relatively stable prevalence.

There are several limitations of this study. First, the current results only report 51 countries globally, with limited generalizability considering the lack of data in many countries. $\mathrm{HCV}$ prevalence is higher in low- and middle-income countries, yet reports from these regions (e.g., Sub-Saharan, Eastern Europe, Middle East, North Africa) are inadequate. Thus, more studies from these regions are still needed in these regions. Second, this study has high heterogeneity. Although we explored some sources of heterogeneity such as geographic region, study year, concurrent HIV infection status, income level of countries, controlled the included participants, testing method, outcomes, and study type. However, to comprehensively evaluate the sources of heterogeneity is still limited by the lack of information in most original studies including age distribution, gender, other concurrent high-risk behaviors, or status. Additionally, HCV is less tested among MSM in the early 1990s; furthermore, the sensitivities and specificities of different arrays used in different regions and different time periods for $\mathrm{HCV}$ diagnosis may also cause variability. Third, there is a lack of information on some important variables such as PWID. Although it is hindered by the precision in PWID ascertainment in original articles, the PWID status would provide more valuable information as expected. Finally, publication bias was present among studies used to pool the prevalence in MSM population indicating studies with a higher HCV prevalence tend to be more likely to be published. This publication bias may, thus, overestimate the actual HCV prevalence in MSM.

\section{REFERENCES}

1. World Health Organization. Global Hepatitis Report, 2017. (2017). Available online at: https://www.who.int/hepatitis/publications/global-hepatitisreport2017/en/ (accessed September 16, 2020).

2. Westbrook RH, Dusheiko G. Natural history of hepatitis C. J Hepatol. (2014) 61(1 Suppl):S58-68. doi: 10.1016/j.jhep.2014.07.012

3. World Health Organization. Guidelines for the Care and Treatment of Persons Diagnosed With Chronic Hepatitis C Virus Infection. (2018). Available

\section{CONCLUSION AND IMPLICATION}

This study reveals a consistently higher HCV prevalence in Central America and Southeast Asia in the MSM population. There is also a much higher HCV prevalence in HIV-positive MSM than in HIV-negative MSM. Based on these findings, behavioral counseling, regular HCV testing, and treatment are urgently needed in the above key population and key region. In addition, given the upward trend of HCV incidence and increasing sexual risk behaviors in developed countries, there is a continued need to reinforce risk-reduction intervention for all the MSM.

\section{DATA AVAILABILITY STATEMENT}

The original contributions presented in the study are included in the article/Supplementary Material, further inquiries can be directed to the corresponding author/s.

\section{AUTHOR CONTRIBUTIONS}

JW, YZhe, and JR designed the study. JW and YZhe developed and implemented the search protocol and wrote the manuscript. YZhe, MY, YZho, YL, JR, and JW abstracted data with JW acting as a tiebreaker at all the stages. YZhe developed the global rates map. JW supervised the whole study and responsible for the decision to submit the manuscript. All authors revised the manuscript from the preliminary draft to submission.

\section{FUNDING}

This study was supported by grants from the Mega Project of National Science and Technology for the 13th Five-Year Plan of China (2018ZX10721102-003-006 and 2018ZX10715013-003-003) and the National Natural Science Foundation of China (71904170). The funders play no role in the study design, collection, analysis, interpretation of data, the writing of this article, or the decision to submit it for publication.

\section{SUPPLEMENTARY MATERIAL}

The Supplementary Material for this article can be found online at: https://www.frontiersin.org/articles/10.3389/fmed. 2021.774793/full\#supplementary-material

online at: https://www.who.int/hepatitis/publications/hepatitis-c-guidelines2018/en/ (accessed September 16, 2020).

4. Wandeler G, Gsponer T, Bregenzer A, Günthard HF, Clerc O, Calmy A, et al. Hepatitis C virus infections in the Swiss HIV Cohort Study: a rapidly evolving epidemic. Clin Infect Dis. (2012) 55:1408-16. doi: 10.1093/cid/cis694

5. Urbanus AT, van de Laar TJ, Stolte IG, Schinkel J, Heijman T, Coutinho $\mathrm{RA}$, et al. Hepatitis $\mathrm{C}$ virus infections among HIV-infected men who have sex with men: an expanding epidemic. AIDS. (2009) 23:F17. doi: 10.1097/QAD.0b013e32832e5631 
6. Foster AL, Gaisa MM, Hijdra RM, Turner SS, Morey TJ, Jacobson KB, et al. Shedding of hepatitis $\mathrm{C}$ virus into the rectum of HIV-infected men who have sex with men. Clin Infect Dis. (2017) 64:284-8. doi: 10.1093/cid/ciw740

7. Apers L, Vanden Berghe W, De Wit S, Kabeya K, Callens S, Buyze J, et al. Risk factors for HCV acquisition among HIV-positive MSM in Belgium. J Acquir Immune Defic Syndr. (2015) 68:585-93. doi: 10.1097/QAI.0000000000000528

8. Newsum AM, van Rooijen MS, Kroone M, Bruisten SM, Matser A, Hogewoning A, et al. Stable low hepatitis $C$ virus antibody prevalence among HIV-negative men who have sex with men attending the sexually transmitted infection outpatient clinic in Amsterdam, 2007 to 2017. Sex Transm Dis. (2018) 45:813-7. doi: 10.1097/OLQ.0000000000000877

9. Hoornenborg E, Coyer L, Boyd A, Achterbergh RCA, van der Loeff MFS, Bruisten S, et al. High incidence of HCV in HIV-negative men who have sex with men using pre-exposure prophylaxis. J Hepatol. (2020) 72:85564. doi: 10.1016/j.jhep.2019.11.022

10. Charre C, Cotte L, Kramer R, Miailhes P, Godinot M, Koffi J, et al. Hepatitis C virus spread from HIV-positive to HIV-negative men who have sex with men. PLoS ONE. (2018) 13:e0190340. doi: 10.1371/journal.pone.0190340

11. Jin F, Dore GJ, Matthews G, Luhmann N, Macdonald V, Bajis S, et al. Prevalence and incidence of hepatitis $C$ virus infection in men who have sex with men: a systematic review and meta-analysis. Lancet Gastroenterol Hepatol. (2021) 6:39-56. doi: 10.1016/S2468-1253(20)30303-4

12. Moher D, Shamseer L, Clarke M, Ghersi D, Liberati A, Petticrew M, et al. Preferred reporting items for systematic review and meta-analysis protocols (PRISMA-P) 2015 statement. Syst Rev. (2015) 4:1. doi: 10.1186/2046-4053-4-1

13. Ganatra B, Gerdts C, Rossier C, Johnson BR Jr, Tunçalp Ö, Assifi A, et al. Global, regional, and subregional classification of abortions by safety, 201014: estimates from a Bayesian hierarchical model. Lancet. (2017) 390:237281. doi: 10.1016/S0140-6736(17)31794-4

14. Modesti PA, Reboldi G, Cappuccio FP, Agyemang C, Remuzzi G, Rapi S, et al. Panethnic differences in blood pressure in Europe: a systematic review and meta-analysis. PLOS ONE. (2016) 11:e0147601. doi: 10.1371/journal.pone.0147601

15. Stang A. Critical evaluation of the Newcastle-Ottawa scale for the assessment of the quality of nonrandomized studies in meta-analyses. Eur J Epidemiol. (2010) 25:603-5. doi: 10.1007/s10654-010-9491-Z

16. Barendregt JJ, Doi SA, Lee YY, Norman RE, Vos T. Metaanalysis of prevalence. J Epidemiol Community Health. (2013) 67:974-8. doi: 10.1136/jech-2013-203104

17. Hess KL, Crepaz N, Rose C, Purcell D, Paz-Bailey G. Trends in sexual behavior among men who have sex with men (MSM) in high-income countries, 1990-2013: a systematic review. AIDS Behav. (2017) 21:281134. doi: 10.1007/s10461-017-1799-1

18. World Health Organization. Hepatitis C. (2020). Available online at: https:// www.who.int/news-room/fact-sheets/detail/hepatitis-c (accessed September 16, 2020).

19. Polaris Observatory HCV Collaborators. Global prevalence and genotype distribution of hepatitis C virus infection in 2015: a modelling study. Lancet Gastroenterol Hepatol. (2017) 2:161-76. doi: 10.1016/S2468-1253(16) 30181-9

20. Degenhardt L, Peacock A, Colledge S, Leung J, Grebely J, Vickerman $\mathrm{P}$, et al. Global prevalence of injecting drug use and sociodemographic characteristics and prevalence of HIV, HBV, and HCV in people who inject drugs: a multistage systematic review. Lancet Glob Health. (2017) 5:e1192e207. doi: 10.1016/S2214-109X(17)30375-3

21. Beijer U, Wolf A, Fazel S. Prevalence of tuberculosis, hepatitis C virus, and HIV in homeless people: a systematic review and meta-analysis. Lancet Infect Dis. (2012) 12:859-70. doi: 10.1016/S1473-3099(12)70177-9

22. Dolan K, Wirtz AL, Moazen B, Ndeffo-Mbah M, Galvani A, Kinner SA, et al. Global burden of HIV, viral hepatitis, and tuberculosis in prisoners and detainees. Lancet. (2016) 388:1089-102. doi: 10.1016/s0140-6736(16)30466-4

23. Midgard H, Weir A, Palmateer N, Lo Re 3rd V, Pineda JA, Macías J, et al. HCV epidemiology in high-risk groups and the risk of reinfection. J Hepatol. (2016). 65(1 Suppl): S33-s45. doi: 10.1016/j.jhep.2016.07.012

24. Sonderup MW, Afihene M, Ally R, Apica B, Awuku Y, Cunha L, et al. Hepatitis C in sub-Saharan Africa: the current status and recommendations for achieving elimination by 2030. Lancet Gastroenterol Hepatol. (2017) 2:9109. doi: 10.1016/s2468-1253(17)30249-2
25. Gower E, Estes C, Blach S, Razavi-Shearer K, Razavi H. Global epidemiology and genotype distribution of the hepatitis $\mathrm{C}$ virus infection. J Hepatol. (2014) 61(1 Suppl): S45-57. doi: 10.1016/j.jhep.2014.07.027

26. Colby D, Trang NNN, Lan HTX, Nguyen T, Thien DD, Mai T, et al. Prevalence of sexually transmitted diseases, HIV, and hepatitis among male sex workers in Ho Chi Minh City, Vietnam. Int J Infect Dis. (2012) 16:e332. doi: 10.1016/j.ijid.2012.05.388

27. Wansom T, Pinyakorn S, Kolsteeg CJ, Kroon E, Sacdalan CP, Chomchey N, et al. Brief report: group sex and methamphetamine use fuel an explosive epidemic of hepatitis C among HIV-infected men who have sex with men in Bangkok, Thailand. J Acquir Immune Defic Syndr. (2020) 84:3315. doi: 10.1097/qai.0000000000002356

28. Nadol P, O'Connor S, Duong H, Mixson-Hayden T, Tram TH, Xia GL, et al. High hepatitis $\mathrm{C}$ virus (HCV) prevalence among men who have sex with men (MSM) in Vietnam and associated risk factors: 2010 Vietnam Integrated Behavioural and Biologic Cross-Sectional Survey. Sex Transm Infect. (2016) 92:542-9. doi: 10.1136/sextrans-2015-052518

29. Platt L, Easterbrook P, Gower E, McDonald B, Sabin K, McGowan C, et al. Prevalence and burden of HCV co-infection in people living with HIV: a global systematic review and meta-analysis. Lancet Infect Dis. (2016) 16:797808. doi: 10.1016/s1473-3099(15)00485-5

30. MacGregor L, Martin NK, Mukandavire C, Hickson F, Weatherburn P, Hickman M, et al. Behavioural, not biological, factors drive the HCV epidemic among HIV-positive MSM: HCV and HIV modelling analysis including HCV treatment-as-prevention impact. Int J Epidemiol. (2017) 46:158292. doi: 10.1093/ije/dyx075

31. Taylor LE, Swan T, Mayer KH. HIV coinfection with hepatitis C virus: evolving epidemiology and treatment paradigms. Clin Infect Dis. (2012). 55(suppl_1):S33-42. doi: 10.1093/cid/cis367

32. Frias M, Rivero-Juarez A, Tellez F, Perez-Perez M, Camacho A, Machuca I, et al. Spontaneous clearance of chronic hepatitis $\mathrm{C}$ is rare in $\mathrm{HIV}$-infected patients after effective use of combination antiretroviral therapy. PLoS ONE. (2017) 12:e0177141. doi: 10.1371/journal.pone.0177141

33. Traeger MW, Cornelisse VJ, Asselin J, Price B, Roth NJ, Willcox J, et al Association of HIV preexposure prophylaxis with incidence of sexually transmitted infections among individuals at high risk of HIV infection. JAMA. (2019) 321:1380-90. doi: 10.1001/jama.2019.2947

34. Macgregor L, Desai M, Martin NK, Nicholls J, Hickson F, Weatherburn P, et al. Scaling up screening and treatment for elimination of hepatitis $\mathrm{C}$ among men who have sex with men in the era of HIV pre-exposure prophylaxis. EClinicalMedicine. (2020) 19:100217. doi: 10.1016/j.eclinm.2019.11.010

35. van der Helm JJ, Prins M, del Amo J, Bucher HC, Chêne G, Dorrucci M, et al. The hepatitis C epidemic among HIV-positive MSM: incidence estimates from 1990 to 2007. AIDS. (2011) 25:1083-91. doi: 10.1097/QAD.0b013e3283471cce

36. van Santen DK, van der Helm JJ, Del Amo J, Meyer L, D’Arminio Monforte A, Price $\mathrm{M}$, et al. Lack of decline in hepatitis $\mathrm{C}$ virus incidence among HIVpositive men who have sex with men during 1990-2014. J Hepatol. (2017) 67:255-62. doi: 10.1016/j.jhep.2017.03.038

37. Chaillon A, Sun X, Cachay ER, Looney D, Wyles D, Garfein RS, et al. Primary incidence of hepatitis $\mathrm{C}$ virus infection among HIV-infected men who have sex with men in San Diego, 2000-2015. Open Forum Infect Dis. (2019). 6:ofz160. doi: 10.1093/ofid/ofz160

38. Tsai JC, Hung CC, Chang SY, Liu WC, Wu CH, Su YC, et al. Increasing incidence of recent hepatitis $\mathrm{C}$ virus infection among persons seeking voluntary counselling and testing for HIV and sexually transmitted infections in Taiwan. BMJ Open. (2015) 5:e008406. doi: 10.1136/bmjopen-2015-008406

39. Ho SY, Su LH, Sun HY, Huang YS, Chuang YC, Huang MH, et al. Trends of recent hepatitis $\mathrm{C}$ virus infection among HIV-positive men who have sex with men in Taiwan, 2011-2018. EClinicalMedicine. (2020) 24:100441. doi: 10.1016/j.eclinm.2020.100441

40. Hibbert MP, Brett CE, Porcellato LA, Hope VD. Psychosocial and sexual characteristics associated with sexualised drug use and chemsex among men who have sex with men (MSM) in the UK. Sex Transm Infect. (2019) 95:34250. doi: 10.1136/sextrans-2018-053933

41. Wong NS, Kwan TH, Lee KCK, Lau JYC, Lee SS. Delineation of chemsex patterns of men who have sex with men in association with their sexual networks and linkage to HIV prevention. Int J Drug Policy. (2020) 75:102591. doi: 10.1016/j.drugpo.2019.10.015 
42. Lim SH, Guadamuz TE, Wei C, Chan R, Koe S. Factors associated with unprotected receptive anal intercourse with internal ejaculation among men who have sex with men in a large internet sample from Asia. AIDS Behav. (2012) 16:1979-87. doi: 10.1007/s10461-012-0233-y

43. Logan L, Fakoya I, Howarth A, Murphy G, Johnson AM, Rodger AJ, et al. Combination prevention and HIV: a cross-sectional community survey of gay and bisexual men in London, October to December 2016. Euro Surveill. (2019) 24:1800312. doi: 10.2807/1560-7917.Es.2019.24.25. 1800312

44. Paz-Bailey G, Hall HI, Wolitski RJ, Prejean J, Van Handel MM, Le B, et al. HIV testing and risk behaviors among gay, bisexual, and other men who have sex with men-United States. MMWR Morb Mortal Wkly Rep. (2013) 62:958. doi: 10.1186/1471-2458-13-1099

45. Cowan SA, Gerstoft J, Haff J, Christiansen AH, Nielsen J, Obel N. Stable incidence of HIV diagnoses among Danish MSM despite increased engagement in unsafe sex. J Acquir Immune Defic Syndr. (2012) 61:10611. doi: 10.1097/QAI.0b013e31825af890

46. Lattimore S, Thornton A, Delpech V, Elford J. Changing patterns of sexual risk behavior among London gay men: 1998-2008. Sex Transm Dis. (2011) 38:221-9. doi: 10.1097/OLQ.0b013e3181f2ebe1

47. Casalino E, Choquet C, Leleu A, Hellmann R, Wargon M, Juillien $\mathrm{G}$, et al. Trends in condom use and risk behaviours after sexual exposure to HIV: a seven-year observational study. PLoS ONE. (2014) 9:e104350. doi: 10.1371/journal.pone.0104350

48. Jansen IA, Geskus RB, Davidovich U, Jurriaans S, Coutinho RA, Prins M, et al. Ongoing HIV-1 transmission among men who have sex with men in Amsterdam: a 25-year prospective cohort study. AIDS. (2011) 25:493501. doi: 10.1097/QAD.0b013e328342fbe9
49. Chen CH Yu ML. Evolution of interferon-based therapy for chronic hepatitis C. Hepat Res Treat. (2010) 2010:140953. doi: 10.1155/2010/140953

50. Kabiri M, Jazwinski AB, Roberts MS, Schaefer AJ, Chhatwal J. The changing burden of hepatitis $C$ virus infection in the United States: model-based predictions. Ann Intern Med. (2014) 161:170-80. doi: 10.7326/m14-0095

51. Moyer VA, on behalf of the U.S. Preventive Services Task Force. Screening for hepatitis C virus infection in adults: US Preventive Services Task Force recommendation statement. Ann Intern Med. (2013) 159:34957. doi: 10.7326/0003-4819-159-5-201309030-00672

Conflict of Interest: The authors declare that the research was conducted in the absence of any commercial or financial relationships that could be construed as a potential conflict of interest.

Publisher's Note: All claims expressed in this article are solely those of the authors and do not necessarily represent those of their affiliated organizations, or those of the publisher, the editors and the reviewers. Any product that may be evaluated in this article, or claim that may be made by its manufacturer, is not guaranteed or endorsed by the publisher.

Copyright (c) 2021 Zheng, Ying, Zhou, Lin, Ren and Wu. This is an open-access article distributed under the terms of the Creative Commons Attribution License (CC $B Y)$. The use, distribution or reproduction in other forums is permitted, provided the original author(s) and the copyright owner(s) are credited and that the original publication in this journal is cited, in accordance with accepted academic practice. No use, distribution or reproduction is permitted which does not comply with these terms. 